\title{
Anterior Cervical Corpectomy and the Operating Team: A Controversy?
}

\author{
Alexandrina Nikova ${ }^{1}$ Theodossios Birbilis ${ }^{1}$ \\ ${ }^{1}$ Department of Neurosurgery, Democritus University of Thrace, \\ Alexandroupolis, Greece
}

Indian J Neurosurg 2018;7:8-15

\begin{abstract}
Address for correspondence Alexandrina Nikova, Department of Neurosurgery, Democritus University of Thrace, Dragana 68100, Alexandroupolis, Greece (e-mail: nikovaalex@gmail.com).
\end{abstract}

\author{
Abstract \\ Keywords \\ - cervical myelopathy \\ - improvement \\ - outcome \\ - surgery \\ - quality of life
}

Cervical myelopathy is multifactorial disease that can lead to many dysfunctions. Surgical treatment is believed to be the best healing choice. The authors searched the published data on Medline on this subject and found a difference between the neurosurgeons and orthopaedics on the topic of anterior corpectomy for cervical myelopathy. The difference between the orthopaedics and neurosurgeons is not big, but it could be relevant to the final outcome, which appears to be better in the neurosurgeons. The complication rate is also variable between the groups, with lower rates of complication reported by the neurosurgeons. Therefore, despite the fact that the postoperative outcome depends on many factors, such as preoperative condition, additional comorbidities, age, and lifestyle, this article also finds that the surgical team, after comparing basic techniques that the team used for anterior cervical corpectomy (ACC), is also responsible to some extent. This, however, is not a competition, and future cooperation between the teams might be beneficial for all.

\section{Introduction}

Cervical myelopathy (CM) was first introduced to the scene of pathology of the cervical spine by Lees and Turner and by Clarke and Robinson. ${ }^{1}$

$\mathrm{CM}$ is indeed a progressive pathologic state based on reduction in the spinal canal followed by cord dysfunction and, in some cases, paralysis. It is linked to spinal cord compression or ischemia and degenerative changes. As a result, there is an injury to the spinal cord, of the vascular and nerve function. Because of that, those patients' quality of life is observed to decrease constantly without management.

Proper therapy and enhancement of the quality of life are believed to be achieved with surgery, and for this reason, the reviewers aspire to show that the operating team plays a role for the postoperative outcome of those patients.

\section{Methods}

The researchers chose this subject because of the controversial interest that stems from it, as well as the lack of information. The topic, whether orthopaedics or neurosurgeons or both, have better results, and the percentage of complication of each team after corpectomy for CM triggered the initiative to search the published data on Medline. For the analysis, the authors collected published studies between 1991 and 2017 with MesH terms "cervical myelopathy," "neurosurgeons," "orthopaedics," "corpectomy," and "anterior spine surgery." The studies encompass all kinds of age categories, including elderly patients and patients with comorbidities (diabetes, cardiac problems, etc.) and single or/and multilevel CM.

Inclusion criteria for the study were articles on humans; articles written in English; articles providing information on the technique of the corpectomy and, if there are complications, the publishing team to be only from one kind of departmentneurosurgery or orthopaedics-and finally articles with improvement rate based on Japanese Orthopedic Association (JOA) score. After the search, the authors included 47 articles with the aforementioned criteria (23 neurosurgeons and 24 orthopaedics) (- Tables $\mathbf{1}, \mathbf{2}$, - Fig. $\mathbf{1}$ ).

On the other hand, the reviewers excluded letters to editor; comments; case reports; animal trials; articles without abstracts; multicenter studies; most of the reviews and meta-analyses; articles in other than English language; articles that do not show the complications, and/or the received

December 15, 2017 accepted after revision

March 23, 2018

published online

May 15, 2018
DOI https://doi.org/

10.1055/s-0038-1651532. ISSN 2277-954X
Copyright @2018 Neurological

Surgeons' Society of India
License terms

(a) (1) $\ominus \circledast$ 
Table 1 List of studies reported by neurosurgeons

\begin{tabular}{|c|c|c|c|}
\hline Team & $\begin{array}{l}\text { No. of } \\
\text { patients }\end{array}$ & Technique & $\begin{array}{l}\text { Improvement } \\
\text { rate }(\%)\end{array}$ \\
\hline Zaïri et al ${ }^{12}$ & 26 & Titanium cage, plate, bone graft from the corpectomy; ACCF & 100 \\
\hline Acosta et al ${ }^{13}$ & 20 & ACCF; cage, plate, corpectomy graft, or allograft & 83 \\
\hline Shaker et al ${ }^{14}$ & 26 & Oblique corpectomy & 76.9 \\
\hline Koc et al ${ }^{15}$ & 44 & ACCF; iliac graft and plate & 88.6 \\
\hline Thakar et al ${ }^{19}$ & 67 & Central corpectomy; plate and iliac graft & 88.05 \\
\hline Lee et $\mathrm{al}^{20}$ & 22 & Oblique & 70.81 \\
\hline Chibbaro et $\mathrm{al}^{21}$ & 70 & ACCF; iliac graft, plate, and cage & 94.2 \\
\hline Costa et $a^{23}$ & 34 & ACCF; iliac graft and plate & 73.3 \\
\hline Rochhi et al ${ }^{24}$ & 48 & Oblique corpectomy & 85.42 \\
\hline Turel et al ${ }^{25}$ & 28 & Oblique corpectomy & 97.37 \\
\hline Chang et al ${ }^{26}$ & 15 & ACCF; cage and plate & 100 \\
\hline Lau et $\mathrm{al}^{31}$ & 60 & ACCF; cage, plate, and graft from the corpectomy & 95 \\
\hline Ozer et al ${ }^{32}$ & 11 & Open-window corpectomy; iliac or allograft & 100 \\
\hline Duzkalir et al ${ }^{36}$ & 60 & Central corpectomy; fibular and iliac graft & 100 \\
\hline Epstein $^{37}$ & 48 & ACCF; iliac graft or allograft and plate & 89 \\
\hline Epstein and Silvergleide ${ }^{38}$ & 46 & ACCF; plate and iliac graft & 83 \\
\hline Ernestus et $a^{39}$ & 46 & $\begin{array}{l}\text { Central corpectomy; Iliac or corpectomy graft, cage, implants, } \\
\text { and plate }\end{array}$ & 93 \\
\hline Perrini et $\mathrm{al}^{41}$ & 42 & ACCF; cage, plate, iliac and corpectomy graft & 100 \\
\hline Gupta and Rajshekhar ${ }^{43}$ & 33 & Central corpectomy; fibula graft & 90 \\
\hline Kristof et $\mathrm{al}^{50}$ & 42 & ACCF; iliac graft and plate & 79 \\
\hline Kotil and Tari53 & 25 & ACCF; iliac graft and plate & 69 \\
\hline Kumar et al ${ }^{54}$ & 410 & Central corpectomy; iliac or fibula graft & 98 \\
\hline Rajshekhar et al ${ }^{56}$ & 60 & Central corpectomy; cage, plate, and iliac of fibula graft & 100 \\
\hline
\end{tabular}

Abbreviation: ACCF, anterior cervical corpectomy with fusion.

improvement and/or the operative technique; articles from more than one kind of departments or not sufficient operating team, publishing the article; and articles that report improvement based on other than JOA score system. Finally, the authors blindingly excluded articles that were last in the row on Medline, to compare approximately the same numbers of studies, because of the insufficient number of papers from the neurosurgeons (not enough articles that meet the inclusion criteria).

Thereafter, the authors analyzed the data with F-test and $t$-test on Excel.

\section{Surgical Management and Outcome}

Treatment of CM is generally divided into operative and nonoperative. ${ }^{1,2}$ Operative treatment is being considered in presence of symptomatic cord dysfunction or pain and earlier operation in case of rapid neurologic deterioration. ${ }^{1}$ Studies show that most patients following surgical treatment have an improvement of their functionality. ${ }^{3}$ There are plenty of surgical options, including anterior and posterior approaches with or without fusion. ${ }^{4}$

The most common posterior technique is laminectomy (LAMT), performed with or without fusion. ${ }^{4}$ Laminoplasty (LAMP), on the other hand, is a posterior approach used to prevent complications with the disadvantage of axial symptoms after surgery. 4,5

On the other hand, anterior approach (corpectomy or discectomy) is thought to have less complications, compared with the posterior approach, and the advantage of straight excision of the pathology, better fusion and reconstruction of deformities, relief of the spinal artery, and neck-pain restoration. ${ }^{6,7}$ Rates of improvement and fusion are the same between corpectomy and discectomy, except the level of complications, ${ }^{8,9}$ whereas other studies report that corpectomy has better general recovery rate than others. ${ }^{10}$ Because of this controversy, the authors chose to analyze the cervical corpectomy.

\section{Corpectomy Technique and Rate of Improvement}

Regarding the improving rate, the worldwide guidelines ${ }^{11}$ report that these techniques have similar outcomes. The authors of this study, however, investigating the surgical group for corpectomy suggest that the outcome is highly dependable on the operating team, while the number of patients do not play a major role to the outcome.

Concluding from the reviewed studies, the outcome for $\mathrm{CM}$ after surgery is quite promising. The general improving 
Table 2 List of studies reported by orthopaedic surgeons

\begin{tabular}{|c|c|c|c|}
\hline Study & No. of patients & Technique & Improvement rate (\%) \\
\hline Shaker et al ${ }^{14}$ & 8 & ACCF; fibula graft and plate & 100 \\
\hline Aramomi et al ${ }^{17}$ & 9 & Anterior pedicle; fibula graft, plate & 82.79 \\
\hline Shibuya et al ${ }^{18}$ & & Subtotal corpectomy; iliac graft & 55.5 \\
\hline Ying et $a^{62}$ & 178 & $\begin{array}{l}\text { Corpectomy with preserved vertebral wall; cage, } \\
\text { plate, and iliac graft }\end{array}$ & 76.49 \\
\hline Lin et $\mathrm{al}^{22}$ & 63 & ACCF or skip-level corpectomy; cage and plate & 93.23 \\
\hline Gao et $\mathrm{al}^{27}$ & 145 & ACCF; cage, plate, iliac or corpectomy graft & 62.5 \\
\hline Huang et $\mathrm{al}^{28}$ & 19 & ACCF; allograft or corpectomy graft, plate & 71.4 \\
\hline Yang et al ${ }^{29}$ & 67 & ACCF; cage, plate, corpectomy graft & 85.64 \\
\hline Liu et $\mathrm{al}^{30}$ & 24 & Subtotal corpectomy; iliac graft and plate & 67.09 \\
\hline Yan et al ${ }^{33}$ & 75 & ACCF; cage, plate, and corpectomy graft & 82.05 \\
\hline Williams et a $\left.\right|^{10}$ & 24 & ACCF; plate, iliac graft & 62.35 \\
\hline Fengbin et $\mathrm{al}^{34}$ & 58 & ACCF; cage, plate, and corpectomy graft & 58 \\
\hline Mao et $\mathrm{al}^{35}$ & 42 & ACCF; cage, plate, and corpectomy graft & 86.96 \\
\hline Niu et $\mathrm{al}^{40}$ & 23 & Key hole; allograft or corpectomy graft & 83 \\
\hline Li et al ${ }^{42}$ & 39 & Segmental ACCF; cage, corpectomy graft, and plate & 88.16 \\
\hline Gupta and Rajshekhar ${ }^{43}$ & 15 & ACCF; cage, implants, plate, corpectomy graft & 81.82 \\
\hline Li et al ${ }^{45}$ & 39 & Segmental ACCF; iliac graft, cage, and plate & 87.1 \\
\hline Liu et $a^{46}$ & 28 & Hybrid; implant, cage, plate, and corpectomy graft & 55.83 \\
\hline Tateiwa et al ${ }^{47}$ & 27 & Subtotal corpectomy; fibula graft & 62 \\
\hline Zhang et al ${ }^{48}$ & 117 & ACCF; cage, corpectomy graft & 90 \\
\hline Wada et $a^{49}$ & 23 & Subtotal corpectomy; iliac or fibula graft & 82.41 \\
\hline Kimura et al ${ }^{51}$ & 16 & ACCF; iliac or fibula graft and plate & 78.95 \\
\hline Odate et $\mathrm{al}^{52}$ & 42 & Hybrid; plate and fibula graft & 53.8 \\
\hline Lu et $\mathrm{al}^{55}$ & 51 & ACCF; cage, plate, and corpectomy graft & 69.7 \\
\hline
\end{tabular}

Abbreviation: ACCF, anterior cervical corpectomy with fusion.

\section{FLOW CHART}

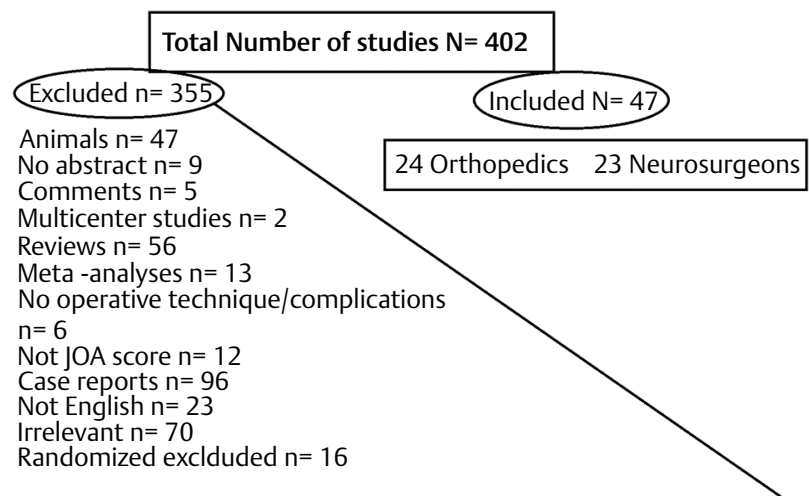

Fig. 1 Flowchart. JOA, Japanese Orthopedic Association.

rate is mainly more than $50 \%$ with good fusion rate and improvement of the quality, results comparable to those by the Congress of Neurological Surgeons. ${ }^{11}$ However, it should be taken into consideration the fact that neurosurgeons have better rate of improvement than the orthopaedics (all of the rates are calculated on the principle: Sum of improving rates/
Number of studies). As it could be seen in - Table $\mathbf{3 - 5}$, $^{12-56}$ the average rate of improvement after corpectomy of the neurosurgeons is $89.56 \%$ whereas the same rate for the orthopaedics is $75.95 \%$.

Further analyzation of the techniques shows that orthopaedics use only fusion for the corpectomy with or without instrumentation, whereas some of the neurosurgeons do not. The improving rate after fusion is $89.70 \%$ for the neurosurgeons and $75.95 \%$ for the orthopaedics. Furthermore, the F-test and $t$-test, as it could be seen in - Tables $\mathbf{4}$ and $\mathbf{5}$, support that the fusion rate of the orthopaedics and neurosurgeons is not equal. The authors performed these tests for the four categories-corpectomy with fusion, fusion with graft only, with cage and plate, and with plate only-and all these showed that these categories are not equal. The fusion is further analyzed, based on the used graft, as is shown in - Table 6 that shows that fibula autograft fusion has better results in orthopaedics whereas every other autograft or allograft has better results in neurosurgeons.

Finally, as the authors analyzed the technique used for the anterior approach, it seems that the most common technique-anterior cervical corpectomy with fusion 
Table 3 Improving rate in orthopaedics and neurosurgery ${ }^{12-56}$

\begin{tabular}{|l|l|l|}
\hline Criteria & $\begin{array}{l}\text { Neurosurgeon } \\
\text { Mean value of improvement }\end{array}$ & $\begin{array}{l}\text { Orthopaedics } \\
\text { Mean value of improvement }\end{array}$ \\
\hline $\begin{array}{l}\text { Average improving rate based } \\
\text { on JOA score }\end{array}$ & $89.56 \%$ & $75.95 \%$ \\
\hline Corpectomy with fusion & $\mathrm{N}^{\mathrm{a}}=20(89.7 \%)$ & $\mathrm{N}=24(75.95 \%)$ \\
\hline Corpectomy without fusion & $\mathrm{N}=3(86.56 \%)$ & $\mathrm{N}=0$ \\
\hline Fusion with cage (and plate) & $\mathrm{N}=8(95.65 \%)$ & $\mathrm{N}=13(78.74 \%)$ \\
\hline Fusion with plate only & $\mathrm{N}=7(81.42 \%)$ & $\mathrm{N}=7(75.08 \%)$ \\
\hline Fusion with screw only & $\mathrm{N}=2(85.41 \%)$ & $\mathrm{N}=0$ \\
\hline Fusion without graft & $\mathrm{N}=1(100 \%)$ & $\mathrm{N}=0$ \\
\hline Fusion with graft only & $\mathrm{N}=3(96 \%)$ & $\mathrm{N}=4(70.73 \%)$ \\
\hline
\end{tabular}

Abbreviation: JOA, Japanese Orthopedic Association.

${ }^{\mathrm{a}} \mathrm{N}$, number of studies.

Note: Mean value of improvement $=$ Sum of the improving rates reported by every study based on JOA score/Number of studies.

Table 4 F-test of corpectomy with fusion

\begin{tabular}{|l|l|l|}
\hline \multicolumn{3}{|c|}{ F-test: Two-sample for variances } \\
\hline & $\begin{array}{l}\text { Corpectomy } \\
\text { with fusion }\end{array}$ & $\begin{array}{l}\text { Corpectomy with } \\
\text { fusion }\end{array}$ \\
\hline Mean & 89,698 & 75,94875 \\
\hline Variance & 106,7223 & 187,8816 \\
\hline Observations & 20 & 24 \\
\hline df & 19 & 23 \\
\hline F & 0,56803 & \\
\hline P (F $\leq f)$ one-tail & 0,10721 & \\
\hline F critical one-tail & 0,470973 & \\
\hline
\end{tabular}

Table 5 t-test of corpectomy with fusion

\begin{tabular}{|l|l|l|}
\hline \multicolumn{3}{|c|}{-test: Two-sample assuming unequal variances } \\
\hline & $\begin{array}{l}\text { Corpectomy } \\
\text { with fusion }\end{array}$ & $\begin{array}{l}\text { Corpectomy with } \\
\text { fusion }\end{array}$ \\
\hline Mean & 89,698 & 75,94875 \\
\hline Variance & 106,7223 & 187,8815592 \\
\hline Observations & 20 & 24 \\
\hline $\begin{array}{l}\text { Hypothesized } \\
\text { mean difference }\end{array}$ & 0 & \\
\hline df & 42 & \\
\hline$t$ stat & 3,789453 & \\
\hline$P(T \leq t)$ one-tail & 0,000238 & \\
\hline$t$ critical one-tail & 1,681952 & \\
\hline$P(T \leq t)$ two-tail & 0,000476 & \\
\hline$t$ critical two-tail & 2,018082 & \\
\hline
\end{tabular}

(ACCF)-has better improving rate in the neurosurgical group rather than in orthopaedics. ACCF actually means a total incision of the pathology that requires fusion (graft or cage) for spinal stabilization. ${ }^{57}$ Oblique corpectomy, on the other hand, is a technique that does not require grafting
Table 6 Graft techniques and improving rate $\mathrm{r}^{12-56,62}$

\begin{tabular}{|l|l|l|}
\hline $\begin{array}{l}\text { Fusion with graft } \\
\text { technique }\end{array}$ & $\begin{array}{l}\text { Improving rate in } \\
\text { neurosurgery } \\
\text { (Mean value of } \\
\text { improvement, \%) }\end{array}$ & $\begin{array}{l}\text { Improving rate in } \\
\text { orthopaedics } \\
\text { (Mean value of } \\
\text { improvement, \%) }\end{array}$ \\
\hline Iliac autograft only & $\mathrm{N}=7(82.16 \%)$ & $\mathrm{N}=5(69.71 \%)$ \\
\hline $\begin{array}{l}\text { Fibula autograft } \\
\text { only }\end{array}$ & $\mathrm{N}=1(90 \%)$ & $\mathrm{N}=2(91.4 \%)$ \\
\hline $\begin{array}{l}\text { Local bone graft } \\
\text { or iliac autograft }\end{array}$ & $\mathrm{N}=1(93 \%)$ & $\mathrm{N}=0$ \\
\hline $\begin{array}{l}\text { Local bone graft } \\
\text { only }\end{array}$ & $\mathrm{N}=2(97.5 \%)$ & $\mathrm{N}=9(78.2 \%)$ \\
\hline $\begin{array}{l}\text { Fibula or iliac } \\
\text { autograft }\end{array}$ & $\mathrm{N}=3(99.33 \%)$ & $\mathrm{N}=2(80.68 \%)$ \\
\hline $\begin{array}{l}\text { Allograft or other } \\
\text { graft }\end{array}$ & $\mathrm{N}=3(90.67 \%)$ & $\mathrm{N}=2(77.2 \%)$ \\
\hline Implants & $\mathrm{N}=1(93 \%)$ & $\mathrm{N}=2(68.83 \%)$ \\
\hline
\end{tabular}

Abbreviation: $\mathrm{N}$, number of studies.

Note: Mean value of improvement $=$ Sum of the reported improvements/Number of studies.

but also could not treat bilateral symptomatology ${ }^{58}$ Central corpectomy is used mainly for ossification of the posterior longitudinal ligament (PLL) and could be accompanied by graft. ${ }^{54}$ As it can be observed in - Table 7, oblique corpectomy and central corpectomy are techniques adopted by neurosurgeons.

Subtotal corpectomy, as it could be seen, is adopted by the orthopaedic team and represents a partial removal of the vertebral body with fusion.

In the unusual techniques are encompassed hybrid techniques of discectomy and corpectomy, open-window corpectomy, "key hole" technique, and anterior pedicle screw.

All these techniques could be performed with or without a microscope. From the orthopaedic articles, no one reported the use of microscope for the anterior corpectomy, whereas plenty of the neurosurgical articles reported the use of microscope for the operation. 
Table 7 Operative technique and improving rate ${ }^{12-56,62}$

\begin{tabular}{|l|l|l|}
\hline Operative technique & $\begin{array}{l}\text { Improving rate in neurosurgeons } \\
\text { (Mean value, \%) }\end{array}$ & $\begin{array}{l}\text { Improving rate in orthopaedics } \\
\text { (Mean value, \%) }\end{array}$ \\
\hline Oblique corpectomy & $82.63 \%$ & - \\
\hline Subtotal corpectomy & - & $66.75 \%$ \\
\hline Central corpectomy & $94.84 \%$ & - \\
\hline $\begin{array}{l}\text { Anterior cervical corpectomy with fusion } \\
\text { (ACCF) }\end{array}$ & $87.84 \%$ & $77.95 \%$ \\
\hline Segmental ACCF & - & $87.63 \%$ \\
\hline Unusual techniques & $100 \%$ & $74.19 \%$ \\
\hline
\end{tabular}

\section{Complications}

Despite the fact that surgical treatment is prescribed to patients who fulfill the inclusion criteria, many of the patients experience complications. The rate of complication is variable, depending on the patients' characteristics, such as age and other conditions; the surgical technique; and the preexisting condition, and as it stems from this study, it also depends on the surgical team.

Many clinical studies show their complication rates. Saunders et al $^{59}$ report complication rate of $47.5 \%$ after corpectomy. For the same approach, Lian et $\mathrm{al}^{60}$ show rate of complication rate equal to $16.19 \%$ and Perrini et $\mathrm{al}^{41}$ equal to $15 \%$. Liu et al ${ }^{30}$ show complication rate of $18.2 \%$. The report of the complications, however, does not necessarily mean that every surgical technique is accompanied with problems. Thakar et a ${ }^{19}$ and Chibbaro et al, ${ }^{21}$ for instance, do not report complications after surgery. In this study, four articles from the orthopaedics and five from the neurosurgical team reported "no complications."

Other authors, ${ }^{61}$ after detailed research, report the prevalence of every complication, based on the technique.

Until now, however, no article on Medline reports the complication rate, based on the surgical team. The authors of this study searched every kind of complication separately from the general complication rate and found that the incidence of complications is higher in orthopaedics (Sum of complication rates/Number of studies) (-Table 8 ). A few kinds of complications, however, are more frequent in neurosurgeons.

Complications with higher prevalence of neurosurgeons, reported in a single study from one patient, include bleeding (4.35\%), mortality (4.17\%), adjacent segment disease (6.3\%), hoarseness (7.1\%), muscle weakness (3.85\%), and kyphosis (3.8\%). Most of those kinds of complications are reported in multiple studies by orthopaedic teams, but the mean number is lower than the number in neurosurgeons. Complications with higher prevalence of the neurosurgeons, reported in more than one studies and compared with the orthopaedics, include graft fracture (6.85\% neurosurgery, $5.73 \%$ orthopaedics), radiculopathy (6.19\% neurosurgery, $3.64 \%$ orthopaedics), screw back-out (17.79\% neurosurgery, $7.32 \%$ orthopaedics), and Horner's syndrome (29.93\% neurosurgery, 0\% orthopaedics, reported by two studies).

Postoperative problems with equivalent mean score include reoperation ( $7.16 \%$ orthopaedics and $7.68 \%$ neurosurgeons) and pain (7.7\% orthopaedics and $7.7 \%$ neurosurgeons).
Table 8 Complications after corpectomy ${ }^{12-56,62}$

\begin{tabular}{|c|c|c|}
\hline Kind of complication & $\begin{array}{l}\text { Neurosurgery } \\
\text { (\%) }\end{array}$ & $\begin{array}{l}\text { Orthopaedics } \\
\text { (\%) }\end{array}$ \\
\hline Dysphagia & 9.19 & 17.28 \\
\hline Screw loosing & & 35.5 \\
\hline Enterotropic ossification ${ }^{\mathrm{a}}$ & & 10.53 \\
\hline Infection & 6.23 & 7.91 \\
\hline $\begin{array}{l}\text { Bone graft displacement/ } \\
\text { migration }\end{array}$ & 4.75 & 7.05 \\
\hline Delirium $^{a}$ & & 1.96 \\
\hline Pulmonary embolism & 4.35 & 7.1 \\
\hline CSF leak & 2.99 & 6.02 \\
\hline Pseudoarthrosis & 7.92 & 18.89 \\
\hline Screw extrusion ${ }^{a}$ & & 3.33 \\
\hline Esophagus fistula & & 4.35 \\
\hline Laryngeal nerve palsy & 1.49 & 4.17 \\
\hline Dural tear & & 7.14 \\
\hline Hematoma & & 2.38 \\
\hline Hardware failure & & 12.5 \\
\hline Respiratory failure & & 13.57 \\
\hline C5 palsy & 7.9 & 8.42 \\
\hline
\end{tabular}

Abbreviation: CSF, cerebrospinal fluid.

aReported in single study.

Every other kind of postoperative complication is more frequent among orthopaedics (-Table 8). Some of the complications are reported by single studies, but the majority represents an average number.

Concluding to this, orthopaedics have less improvement rate and higher values of the postoperative complications, whereas neurosurgeons report lower rates of complications and better improvement rate, a fact that should end the controversy. The general frequency of every kind of complication, however, is comparable to the one, reported by Wang et al. ${ }^{61}$

\section{Discussion}

The progress of $\mathrm{CM}$ differs among patients. In some cases it follows step-wise way; in other there is an improvement or stabilization and worsening after years. Many studies have 
been made to evaluate the outcome and the postoperative improvement in the patients with CM. More of them suggest a quite better outcome, but the data collected from different studies and trials would be never sufficient to establish a constant result for the postoperative quality of the patients with $\mathrm{CM} .{ }^{62}$ In general, it is believed that the degree of improvement after surgery and the level of functionality depend on the severity of the disease and the time of the surgery and much from the neurological recovery. ${ }^{1,63}$ Decompression procedure results in stabilization or improvement in long-tract spinal cord function. ${ }^{63}$ As expected, the function is better in patients who have good reinstatement of spinal canal dimensions, those without substantial comorbidity, and those who have earlier decompression surgery. For this reason, the authors have come to the conclusion that for the outcome, an important role is played by the surgeon, who performed the procedure.

Recent study by Witiw et $\mathrm{a}^{64}$ states that patients' health is generally improved by surgical therapy for CM. The advantages of the anterior approach, however, are thought to be the better improving rate, the more direct approach to the pathology, better stabilization, and better clinical results. ${ }^{65}$ Corpectomy is believed furthermore to be prevalent in those findings. Patient's recovery rate after anterior corpectomy with or without fusion is reported in every study and seems to be very promising. However, when comparing the both surgical teams, there is an estimated difference of the recovery rate's outcomes. Both are more than $50 \%$, but neurosurgeons seem to be dominant, which could be explained by comparing the training program of both specialties and the used techniques.

In many of the studies are added factors that accompany the improvement of the patients. Arnold et $\mathrm{al}^{66}$ reported that the studied patients improved after surgery, but the outcome is linked to the tobacco use and smokers have lower result compared with nonsmokers. According to studies by Cheng et $\mathrm{al}^{63}$ and Rao et $\mathrm{al}^{67}{ }^{67}$ the postoperative recovery is highly dependable on the age, health status, pathology, and the mode of the surgery. Rao et al pointed the age-related fallout with the myelinated fibers and motor neurons of the spinal cord, and it has been proposed that earlier surgery can improve the neurologic recovery much better. Machino et al ${ }^{68}$ showed through the recovery rate the values of the postoperative JOA compared with the pre-JOA score, indicating that the recovery depends strongly on the age group, but the score in general do not differ much among groups.

On the other hand, researches by Fehling ${ }^{69}$ and $\mathrm{Liu}^{70}$ suggest general improvement in the functional quality of life and status result after surgery no matter the severity of the disease at first as well as the underlying factors. The only "must" that was mentioned, was the appropriate surgical approach. For this reason, it is important the operation be performed by qualified surgeons. This study shows that neurosurgeons have prevalence regarding the improvement rate after corpectomy, except of the cases of fibula graft. This could be explained better by the fact that the routine of the general orthopaedic team is wider (whole skeletomuscular system), whereas the routine of the general neurosurgeons is more limited. Last but not least, the general complication rate of the orthopaedics in this study is higher than the same rate of the neurosurgeons. However, once again because of the everyday practice routine, the complications regarding grafting are lower in the orthopaedic team, whereas the complications from fine structures are lower in neurosurgeons. For this reason, the reviewers believe that the outcome of the $\mathrm{CM}$ is, to some extent, dependable on the operating team. The authors believe that future improvement of this subject could be achieved with the cooperation of the both sites, as it is organized in many medical centers worldwide.

\section{Conclusion}

$\mathrm{CM}$ is multifactor disease resulting in nerve, cord, and vascular dysfunction. Operative treatment of this condition can seriously improve the patient's condition. Not only does it enhance the neurologic function, but it also relieves the pain that the patient experiences. Concluding from different studies and researches, surgical treatment of CM cannot only restrict further worsening of the condition for a certain period, but it also can improve patients' quality of life. For this reason, the surgical team, who would perform the surgery, is very important

\section{Conflict of Interest}

None.

\section{References}

1 Emery SE. Cervical spondylotic myelopathy: diagnosis and treatment. J Am Acad Orthop Surg 2001;9(6):376-388

2 Rhee JM, Shamji MF, Erwin WM, et al. Nonoperative management of cervical myelopathy: a systematic review. Spine 2013;38(22, Suppl 1):S55-S67

3 Komotar RJ, Mocco J, Kaiser MG. Surgical management of cervical myelopathy: indications and techniques for laminectomy and fusion. Spine J 2006;6(6, Suppl):252S-267S

4 Lao L, Zhong G, Li X, Qian L, Liu Z. Laminoplasty versus laminectomy for multi-level cervical spondylotic myelopathy: a systematic review of the literature. J Orthop Surg 2013;8:45

5 Geck MJ, Eismont FJ. Surgical options for the treatment of cervical spondylotic myelopathy. Orthop Clin North Am 2002;33(2):329-348

6 Emery SE. Anterior approaches for cervical spondylotic myelopathy: which? When? How? Eur Spine J 2015;24Suppl 2):150-159

7 Yalamanchili PK, Vives MJ, Chaudhary SB. Cervical spondylotic myelopathy: factors in choosing the surgical approach. Adv Orthop 2012;2012:783762

8 Hussain M, Nassr A, Natarajan RN, An HS, Andersson GB. Corpectomy versus discectomy for the treatment of multilevel cervical spine pathology: a finite element model analysis. Spine J 2012;12(5):401-408

9 Uribe JS, Sangala JR, Duckworth EA, Vale FL. Comparison between anterior cervical discectomy fusion and cervical corpectomy fusion using titanium cages for reconstruction: analysis of outcome and long-term follow-up. Eur Spine J 2009;18(5):654-662

10 Williams KE, Paul R, Dewan Y. Functional outcome of corpectomy in cervical spondylotic myelopathy. Indian J Orthop 2009;43(2):205-209

11 Fehlings MG, Arvin B. Surgical management of cervical degenerative disease: the evidence related to indications, impact, and outcome. J Neurosurg Spine 2009;11(2):97-100 
12 Zaïri F, Aboukais R, Thines L, Allaoui M, Assaker R. Relevance of expandable titanium cage for the treatment of cervical spondylotic myelopathy. Eur Spine J 2012;21(8):1545-1550

13 Acosta FL Jr, Aryan HE, Chou D, Ames CP. Long-term biomechanical stability and clinical improvement after extended multilevel corpectomy and circumferential reconstruction of the cervical spine using titanium mesh cages. J Spinal Disord Tech 2008;21(3):165-174

14 Shaker AS, Addosooki AI, El-Deen MA. Anterior cervical corpectomy with free vascularized fibular graft versus multilevel discectomy and grafting for cervical spondylotic myelopathy. Int J Spine Surg 2015;9:60

15 Koç RK, Menkü A, Akdemir H, Tucer B, Kurtsoy A, Oktem IS. Cervical spondylotic myelopathy and radiculopathy treated by oblique corpectomies without fusion. Neurosurg Rev 2004;27(4):252-258

16 Naderi S, Alberstone CD, Rupp FW, Benzel EC, Baldwin NG. Cervical spondylotic myelopathy treated with corpectomy: technique and results in 44 patients. Neurosurg Focus 1996;1(6):e5, discussion 1, e5

17 Aramomi M, Masaki Y, Koshizuka S, et al. Anterior pedicle screw fixation for multilevel cervical corpectomy and spinal fusion. Acta Neurochir (Wien) 2008;150(6):575-582, discussion 582

18 Shibuya S, Komatsubara S, Oka S, Kanda Y, Arima N, Yamamoto T. Differences between subtotal corpectomy and laminoplasty for cervical spondylotic myelopathy. Spinal Cord 2010;48(3):214-220

19 Thakar S, Mohan D, Furtado SV, et al. Paraspinal muscle morphometry in cervical spondylotic myelopathy and its implications in clinicoradiological outcomes following central corpectomy: clinical article. J Neurosurg Spine 2014;21(2):223-230

20 Lee HY, Lee SH, Son HK, et al. Comparison of multilevel oblique corpectomy with and without image guided navigation for multi-segmental cervical spondylotic myelopathy. Comput Aided Surg 2011;16(1):32-37

21 Chibbaro S, Benvenuti L, Carnesecchi S, et al. Anterior cervical corpectomy for cervical spondylotic myelopathy: experience and surgical results in a series of 70 consecutive patients. J Clin Neurosci 2006;13(2):233-238

22 Lin Q, Zhou X, Wang X, Cao P, Tsai N, Yuan W. A comparison of anterior cervical discectomy and corpectomy in patients with multilevel cervical spondylotic myelopathy. Eur Spine J 2012;21(3):474-481

23 Costa F, Tomei M, Sassi M, et al. Evaluation of the rate of decompression in anterior cervical corpectomy using an intra-operative computerized tomography scan (O-Arm system) Eur Spine J 2012;21(2):359-363

24 Rocchi G, Caroli E, Salvati M, Delfini R. Multilevel oblique corpectomy without fusion: our experience in 48 patients. Spine 2005;30(17):1963-1969

25 Turel MK, Sarkar S, Prabhu K, Daniel RT, Jacob KS, Chacko AG. Reduction in range of cervical motion on serial long-term follow-up in patients undergoing oblique corpectomy for cervical spondylotic myelopathy. Eur Spine J 2013;22(7):1509-1516

26 Chang HC, Tu TH, Chang HK, et al. Hybrid corpectomy and disc arthroplasty for cervical spondylotic myelopathy caused by ossification of posterior longitudinal ligament and disc herniation. World Neurosurg 2016;95:22-30

27 Gao R, Yang L, Chen H, Liu Y, Liang L, Yuan W. Long term results of anterior corpectomy and fusion for cervical spondylotic myelopathy. PLoS One 2012;7(4):e34811

28 Huang JJ, Niu CC, Chen LH, Lai PL, Fu TS, Chen WJ. Anterior cervical spinal surgery for multilevel cervical myelopathy. Chang Gung Med J 2004;27(7):531-541

29 Yang X, Chen Q, Liu L, et al. Comparison of anterior cervical fusion by titanium mesh cage versus nano-hydroxyapatite/ polyamide cage following single-level corpectomy. Int Orthop 2013;37(12):2421-2427

30 Liu J, Chen X, Liu Z, Long X, Huang S, Shu Y. Anterior cervical discectomy and fusion versus corpectomy and fusion in treating two-level adjacent cervical spondylotic myelopathy: a minimum 5-year follow-up study. Arch Orthop Trauma Surg 2015;135(2):149-153

31 Lau D, Chou D, Mummaneni PV. Two-level corpectomy versus three-level discectomy for cervical spondylotic myelopathy: a comparison of perioperative, radiographic, and clinical outcomes. J Neurosurg Spine 2015;23(3):280-289

32 Ozer AF, Oktenoglu T, Cosar M, Sasani M, Sarioglu AC. Longterm follow-up after open-window corpectomy in patients with advanced cervical spondylosis and/or ossification of the posterior longitudinal ligament. J Spinal Disord Tech 2009;22(1):14-20

33 Yan D, Wang Z, Deng S, Li J, Soo C. Anterior corpectomy and reconstruction with titanium mesh cage and dynamic cervical plate for cervical spondylotic myelopathy in elderly osteoporosis patients. Arch Orthop Trauma Surg 2011;131(10):1369-1374

34 Fengbin Y, Jinhao M, Xinyuan L, Xinwei W, Yu C, Deyu C. Evaluation of a new type of titanium mesh cage versus the traditional titanium mesh cage for single-level, anterior cervical corpectomy and fusion. Eur Spine J 2013;22(12):2891-2896

35 Mao N, Wu J, Zhang Y, et al. A comparison of anterior cervical corpectomy and fusion combined with artificial disc replacement and cage fusion in patients with multilevel cervical spondylotic myelopathy. Spine 2015;40(16):1277-1283

36 Duzkalir AH, Istemen I, Okutan MO, Ozdogan S, Senturk S, Yildirim T. Clinical results of median corpectomy in cervical spondylotic patients with myelopathy. Turk Neurosurg 2014;26(1):1-8

37 Epstein NE. Reoperation rates for acute graft extrusion and pseudarthrosis after one-level anterior corpectomy and fusion with and without plate instrumentation: etiology and corrective management. Surg Neurol 2001;56(2):73-80, discussion 80-81

38 Epstein NE, Silvergleide RS. Documenting fusion following anterior cervical surgery: a comparison of roentgenogram versus two-dimensional computed tomographic findings. J Spinal Disord Tech 2003;16(3):243-247

39 Ernestus RI, Koehler S, Raslan F, Rueckriegel SM, Stetter C, Westermaier T. Autologous bone graft versus PEKK cage for vertebral replacement after 1- or 2-level anterior median corpectomy. J Neurosurg Spine 2016;24:309-314

40 Niu CC, Hai Y, Fredrickson BE, Yuan HA. Anterior cervical corpectomy and strut graft fusion using a different method. Spine J 2002;2(3):179-187

41 Perrini P, Gambacciani C, Martini C, Montemurro N, Lepori P. Anterior cervical corpectomy for cervical spondylotic myelopathy: reconstruction with expandable cylindrical cage versus iliac crest autograft. A retrospective study. Clin Neurol Neurosurg 2015;139:258-263

42 Li Z, Guo Z, Hou S, et al. Segmental anterior cervical corpectomy and fusion with preservation of middle vertebrae in the surgical management of 4-level cervical spondylotic myelopathy. Eur Spine J 2014;23(7):1472-1479

43 Gupta A, Rajshekhar V. Functional and radiological outcome in patients undergoing three level corpectomy for multi-level cervical spondylotic myelopathy and ossified posterior longitudinal ligament. Neurol India 2016;64(1):90-96

$44 \mathrm{Lu} \mathrm{T}$, Liu C, Yang B, et al. Single-level anterior cervical corpectomy and fusion using a new 3D-printed anatomy-adaptive titanium mesh cage for treatment of cervical spondylotic myelopathy and ossification of the posterior longitudinal ligament: a retrospective case series study. Med Sci Monit 2017;23:3105-3114 
45 Li Z, Huang J, Zhang Z, Li F, Hou T, Hou S. A comparison of multilevel anterior cervical discectomy and corpectomy in patients with 4-level cervical spondylotic myelopathy: a minimum 2-year follow-up study: multilevel anterior cervical discectomy. Clin Spine Surg 2017;30(5):E540-E546

46 Liu Y, Yu KY, Hu JH. Hybrid decompression technique and two-level corpectomy are effective treatments for three-level cervical spondylotic myelopathy. J Zhejiang Univ Sci B 2009;10(9):696-701

47 Tateiwa Y, Kamimura M, Itoh $\mathrm{H}$, et al. Multilevel subtotal corpectomy and interbody fusion using a fibular bone graft for cervical myelopathy due to ossification of the posterior longitudinal ligament. J Clin Neurosci 2003;10(2):199-207

48 Zhang Y, Quan Z, Zhao Z, et al. Evaluation of anterior cervical reconstruction with titanium mesh cages versus nano-hydroxyapatite/polyamide66 cages after 1 - or 2-level corpectomy for multilevel cervical spondylotic myelopathy: a retrospective study of 117 patients. PLoS One 2014;9(5):e96265

49 Wada E, Suzuki S, Kanazawa A, Matsuoka T, Miyamoto S, Yonenobu K. Subtotal corpectomy versus laminoplasty for multilevel cervical spondylotic myelopathy: a long-term follow-up study over 10 years. Spine 2001;26(13):1443-1447, discussion 1448

50 Kristof RA, Kiefer T, Thudium M, et al. Comparison of ventral corpectomy and plate-screw-instrumented fusion with dorsal laminectomy and rod-screw-instrumented fusion for treatment of at least two vertebral-level spondylotic cervical myelopathy. Eur Spine J 2009;18(12):1951-1956

51 Kimura H, Shikata J, Odate S, Soeda T. Anterior corpectomy and fusion to C2 for cervical myelopathy: clinical results and complications. Eur Spine J 2014;23(7):1491-1501

52 Odate S, Shikata J, Kimura H, Soeda T. Hybrid decompression and fixation technique versus plated 3-vertebra corpectomy for 4-segment cervical myelopathy: analysis of 81 cases with a minimum 2-year follow-up. Clin Spine Surg 2016;29(6):226-233

53 Kotil K, Tari R. Two level cervical corpectomy with iliac crest fusion and rigid plate fixation: a retrospective study with a three-year follow-up. Turk Neurosurg 2011;21(4):606-612

54 Kumar GS, Rajshekhar V. Acute graft extrusion following central corpectomy in patients with cervical spondylotic myelopathy and ossified posterior longitudinal ligament. J Clin Neurosci 2009;16(3):373-377

$55 \mathrm{Lu} \mathrm{J}, \mathrm{Wu} \mathrm{X}$, Li Y, Kong X. Surgical results of anterior corpectomy in the aged patients with cervical myelopathy. Eur Spine J 2008;17(1):129-135

56 Vedantam A, Revanappa KK, Rajshekhar V. Changes in the range of motion of the cervical spine and adjacent segments at $\geq 24$ months after uninstrumented corpectomy for cervical spondylotic myelopathy. Acta Neurochir (Wien) 2011;153(5):995-1001
57 Fessler RG, Steck JC, Giovanini MA. Anterior cervical corpectomy for cervical spondylotic myelopathy. Neurosurgery 1998;43(2):257-265, discussion 265-267

58 George B, Gauthier N, Lot G. Multisegmental cervical spondylotic myelopathy and radiculopathy treated by multilevel oblique corpectomies without fusion. Neurosurgery 1999;44(1):81-90

59 Saunders RL, Bernini PM, Shirreffs TG Jr, Reeves AG. Central corpectomy for cervical spondylotic myelopathy: a consecutive series with long-term follow-up evaluation. J Neurosurg 1991;74(2):163-170

60 Lian XF, Xu JG, Zeng BF, Zhou W, Kong WQ, Hou TS. Noncontiguous anterior decompression and fusion for multilevel cervical spondylotic myelopathy: a prospective randomized control clinical study. Eur Spine J 2010;19(5):713-719

61 Wang T, Tian XM, Liu SK, Wang H, Zhang YZ, Ding WY. Prevalence of complications after surgery in treatment for cervical compressive myelopathy: a meta-analysis for last decade. Medicine (Baltimore) 2017;96(12):e6421

62 Ying Z, Xinwei W, Jing Z, et al. Cervical corpectomy with preserved posterior vertebral wall for cervical spondylotic myelopathy: a randomized control clinical study. Spine 2007;32(14):1482-1487

63 Cheng SC, Yen CH, Kwok TK, Wong WC, Mak KH. Anterior spinal fusion versus laminoplasty for cervical spondylotic myelopathy: a retrospective review. J Orthop Surg (Hong Kong) 2009;17(3):265-268

64 Witiw CD, Tetreault LA, Smieliauskas F, Kopjar B, Massicotte EM, Fehlings MG. Surgery for degenerative cervical myelopathy: a patient-centered quality of life and health economic evaluation. Spine J 2017;17(1):15-25

65 Liu T, Xu W, Cheng T, Yang HL. Anterior versus posterior surgery for multilevel cervical myelopathy, which one is better? A systematic review. Eur Spine J 2011;20(2):224-235

66 Arnold PM, Kopjar B, Tetreault L, Nakashima H, Fehlings MG. 162 Tobacco smoking and outcomes of surgical decompression in patients with symptomatic degenerative cervical spondylotic myelopathy. Neurosurgery 2016;63Suppl 1):165

67 Rao RD, Gourab K, David KS. Operative treatment of cervical spondylotic myelopathy. J Bone Joint Surg Am 2006;88(7):1619-1640

68 Machino M, Yukawa Y, Hida T, et al. Can elderly patients recover adequately after laminoplasty?: a comparative study of 520 patients with cervical spondylotic myelopathy. Spine 2012;37(8):667-671

69 Fehlings MG, Wilson JR, Kopjar B, et al. Efficacy and safety of surgical decompression in patients with cervical spondylotic myelopathy: results of the AOSpine North America prospective multi-center study. J Bone Joint Surg Am 2013;95(18):1651-1658

70 He X, Li H, Liu J, Xu S, Zhang L. The surgical approaches of cervical spondylotic myelopathy and the predictive factors for the surgical outcome. Int J Clin Med 2011;2(2):158-165 